\title{
DISTRIBUTION OF LARVAL TABANIDAE (DIPTERA) IN A SPARTINA ALTERNIFLORA SALT MARSH ${ }^{1}$
}

\author{
By J. C. Dukes, T. D. Edwards and R. C. Axtel1 ${ }^{2,3}$
}

\footnotetext{
Abstract: Larvae of Chrysops fuliginosus Wiedemann and Tabanus nigrovittatus Macquart were recovered from the soil of a regularly flooded salt marsh having Spartina alterniflora Loisel (smooth cordgrass) as the dominant vegetation. The larvae were

${ }^{1}$ This research was supported in part by NOAA, Office of Sea Grant, U. S. Department of Commerce, under Grant No. 2-35178. The U. S. Government is authorized to produce and distribute reprints for governmental purpose not withstanding any copyright notation that may appear hereon. Paper No. 4101 of the Journal Series of the North Carolina State University Agricultural Experiment Station.

${ }^{2}$ Department of Entomology, North Carolina State University, Raleigh, North Carolina 27607, U.S.A.

${ }^{3}$ Research Associate, Research Technician and Professor, respectively.
}

found throughout the sampling area with no consistently greater abundance adjacent to a natural drainage ditch. The larvae were found about as frequently in areas of "tall" as in "short" $S$. alterniflora.

Larvae of the salt marsh Tabanidae are most abundant where living plants maintain uniform moisture conditions which favor the free movement of the larvae (Bailey 1948). Although Bailey confirmed the fact that larvae were widely distributed in the marsh soil, he indicated that the Massachusetts salt marshes which were ditched for mosquito control had greater expanses of suitable larval 
habitat than natural marshes where vast areas were more subject to alternate drying and flooding. Wall \& Doane (1960) found tabanid larvae distributed throughout the salt marshes around Cape Cod, Massachusetts.

Rockel (1969) and Rockel \& Hansens (1970a) utilized emergence traps to determine breeding sites at various distances from drainage ditches in a New Jersey salt marsh. They recovered 3 species of Tabanidae; Chrysops fuliginosus Wiedemann located mostly within $0.9 \mathrm{~m}$ of a ditch, Tabanus lineola Fabricius predominantly located within $4.5 \mathrm{~m}$ of a ditch, and T. nigrovittatus Macquart more uniformly distributed throughout the distance of $9 \mathrm{~m}$ from the ditch. Rockel \& Hansens (1970b), using other sampling methods (Berlese funnels, larviciding), concluded that the larvae of $T$. nigrovittatus and Chrysops spp. (presumably C. fuliginosus) were most abundant below mean high-water level on gently sloping banks where cordgrass was about $0.6 \mathrm{~m}$ tall. From other research conducted between 1960 and 1963 in the New Jersey marshes, Freeman \& Hansens (1972) concluded that a variant (named $T$. sp. 3) of $T$. nigrovittatus were most abundant along the ditch banks and the typical larvae of $T$. nigrovittatus was primarily found in the open shortergrass marsh. This was not supported by data reported by Rockel \& Hansens (1970b) from sampling done subsequently between 1965 and 1967.

We systematically sampled a regularly flooded salt marsh in North Carolina during the spring of 1971 and 1972 in order to determine what species of tabanid larvae were present and whether or not the abundance of larvae was correlated with distance from a natural drainage ditch.

\section{MATERIALS AND METHODS}

The study site was a small portion of the marsh bordering the Newport River in Carteret County, North Carolina (FIG. 1). A nearly straight, natural drainage ditch extended from an upland perimeter ditch through the marsh to the Newport River. The margins of the ditch (within 3-5 m) were dominated by the tall growth form of Spartina alterniflora Loisel (smooth cordgrass) averaging 1$1.5 \mathrm{~m}$ in height. The interior of the marsh (beyond 3-5 m) was dominated by the short form of $S$. alterniflora. The difference in form presumably indicated a difference in degree and duration of inundation by salt water (Adams 1963, Cooper 1969, Mooring et al. 1971). A narrow strip of Juncus roemerianus Scheele (black needle rush) separated the marsh from the upland forested area. Data from a tide gauge in the perimeter ditch indicated

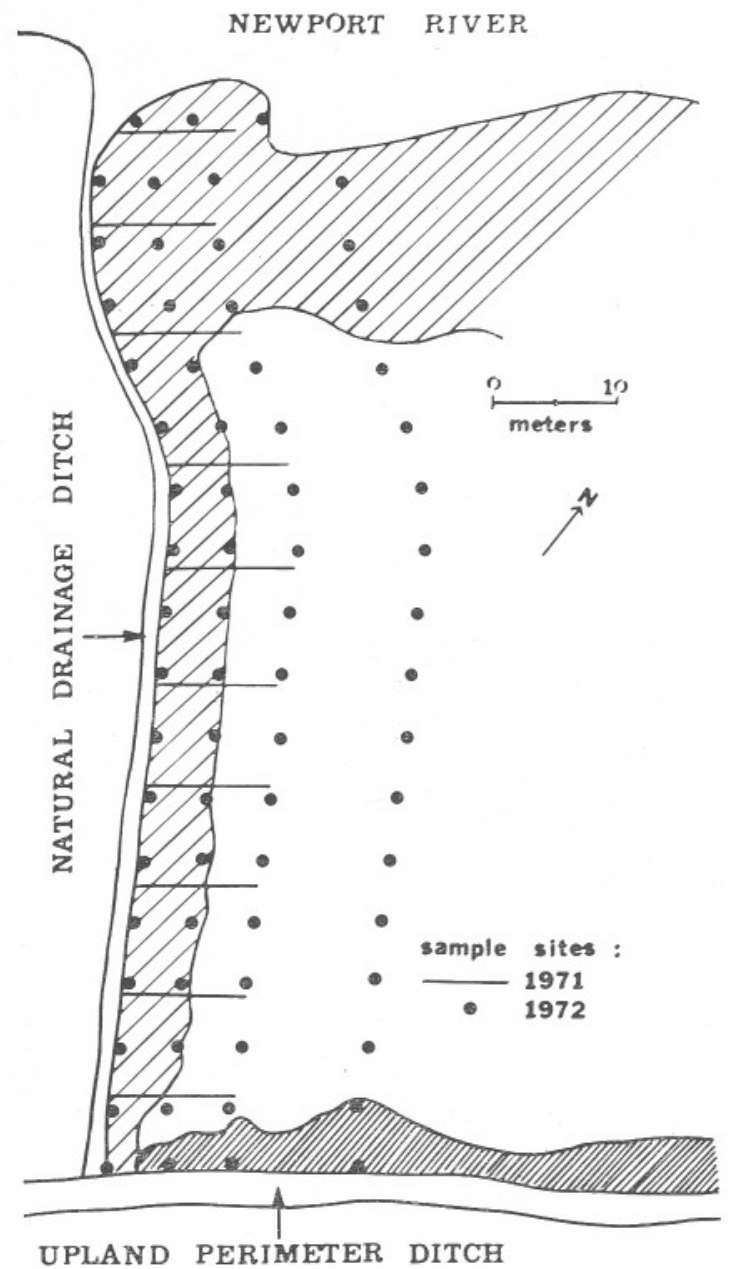

\section{WIG = JUNCUS ROEMERIANUS \\ $Z \bar{Z}=$ SPARTINA ALTERNIFLORA (TALL FORM) \\ =SPARTINA ALTERNIFLORA (SHORT FORM)}

FIG. 1. Diagram of the marsh study area bordering Newport River, Carteret County, North Carolina.

that the water level differed by at least $3 \mathrm{ft}$ between high and low tides. ${ }^{4}$ Surveying the marsh showed that the entire research area was flooded daily by each high tide in every month of the year (TABLE 1).

During April 1971, 10-liter samples of soil from the $S$. alterniflora marsh were taken along 10 transects at right angles to a drainage ditch and at about equal intervals between the perimeter ditch and the edge of the river. For each transect, the soil was removed from a strip approximately $15 \mathrm{~cm}$ wide and $10 \mathrm{~cm}$ deep for a distance of $10 \mathrm{~m}$ from the drainage ditch.

${ }^{4}$ Tide level data in the text and table are given in feet because that unit is accepted by engineers in the United States and the tide gauge equipment was calibrated in feet. 
TABLE 1. Marsh elevations ( $\mathrm{ft}$ ) below monthly mean high tide (MHT) at various distances from the upland perimeter ditch on Newport River, Morehead City, N.C., 1972-1973.

\begin{tabular}{lcccccccccc} 
& \multicolumn{7}{c}{ Level Below MHT AT VARious Distances } & (METERs) & From UPLAND PERIMETER DItch \\
\cline { 2 - 10 } Month & 0 & 10 & 20 & 30 & 40 & 50 & 60 & 70 & 80 & Avg. \\
\hline Mar. & 0.52 & 0.44 & 0.46 & 0.47 & 0.42 & 0.25 & 0.44 & 0.74 & 1.52 & 0.58 \\
Apr. & 0.47 & 0.39 & 0.41 & 0.42 & 0.37 & 0.20 & 0.39 & 0.69 & 1.47 & 0.53 \\
May & 0.73 & 0.65 & 0.67 & 0.68 & 0.63 & 0.46 & 0.65 & 0.95 & 1.73 & 0.60 \\
June & 0.87 & 0.79 & 0.81 & 0.82 & 0.77 & 0.60 & 0.79 & 1.09 & 1.87 & 0.93 \\
July & 0.29 & 0.21 & 0.23 & 0.24 & 0.19 & 0.02 & 0.21 & 0.51 & 1.29 & 0.35 \\
Aug. & 0.18 & 1.10 & 1.12 & 1.13 & 1.08 & 0.91 & 1.10 & 1.40 & 1.28 & 1.03 \\
Sept. & 1.07 & 0.99 & 1.01 & 1.02 & 0.97 & 0.80 & 0.99 & 1.29 & 2.07 & 1.13 \\
Oct. & 1.04 & 0.96 & 0.98 & 0.99 & 0.94 & 0.77 & 0.96 & 1.26 & 2.04 & 1.10 \\
Nov. & 0.89 & 0.81 & 0.83 & 0.84 & 0.79 & 0.62 & 0.81 & 1.11 & 1.89 & 0.95 \\
Dec. & 0.71 & 0.63 & 0.65 & 0.66 & 0.61 & 0.44 & 0.63 & 0.93 & 1.71 & 0.77 \\
Jan. & 0.85 & 0.77 & 0.79 & 0.80 & 0.75 & 0.58 & 0.77 & 1.07 & 1.85 & 0.91 \\
Avg. & 0.69 & 0.70 & 0.72 & 0.73 & 0.68 & 0.51 & 0.70 & 1.00 & 1.70 & 0.81 \\
\hline
\end{tabular}

The soil taken from each meter was washed through a double-screen rack (Edwards et al. 1974) at the laboratory to recover any larvae. After washing, a portion of the vegetative residue from each sample was placed into a Tullgren funnel (60-watt incadescent bulb) to recover larvae not found during the washing process (Wall \& Jamnback 1957, Teskey 1962). The remaining composite of residues from all of the samples from each $10-\mathrm{m}$ strip was dried later in Tullgren funnels to insure complete recovery of all tabanid larvae. Larvae from the 1971 samples were identified by Dr Mac A. Tidwell.

During March and April 1972, the sampling procedures were different but in the same area as 1971. Transects (18) were established at right angles to the drainage ditch and samples $\left(0.1 \mathrm{~m}^{2}\right.$ and approximately $10 \mathrm{~cm}$ deep) were removed from the Spartina sod along each transect at 0,5,10, and $20 \mathrm{~m}$ from the ditch. The sod samples were washed in the field using the wash rack and tide water which was obtained from the ditch by a gasoline powered, high pressure water pump. This allowed greater flexibility in the volume and pressure of the washing water than was possible in 1971. The complete vegetative residue from each sample was placed in Tullgren funnels for recovery of tabanid larvae. The largest larvae were reared to adults utilizing the method described by Roberts (1966) and the smaller larvae were preserved in alcohol. Only those larvae which were large enough and in good condition could be identified reliably to species. We made preliminary determinations according to Jamnback \& Wall (1959) and Teskey (1969). Final determinations were by Dr H. J. Teskey (Entomology Research Institute, Canada) or Dr J. F. Freeman (Castleton State College, Castleton, Vt.). The reared adults were identified by comparison to specimens identified by Dr L. L. Pechuman (Cornell University, Ithaca, N. Y.) and by

TABLE 2. Recovery of larval Tabanidae from soil up to $10 \mathrm{~m}$ from a natural drainage ditch in a Spartina marsh, Newport River, Morehead City, N.C., April 1971. Numbers in parentheses are of Chrysops fuliginosus and numbers without parantheses are of Tabanus nigrovittatus.

\begin{tabular}{|c|c|c|c|c|c|c|c|c|c|c|c|c|}
\hline \multirow{2}{*}{$\begin{array}{c}\text { TranseGT } \\
\text { No.* }\end{array}$} & \multicolumn{10}{|c|}{ METERS FROM DRAINAGE DITCH** } & \multirow[b]{2}{*}{ CR*** } & \multirow[b]{2}{*}{ Total } \\
\hline & 1 & 2 & 3 & 4 & 5 & 6 & 7 & 8 & 9 & 10 & & \\
\hline 1 & 0 & 2 & 1 & 1 & (1) & 0 & 0 & 0 & (1) & (5) & (4) & $4(11)$ \\
\hline 2 & (1) & 1 & $1(1)$ & 2 & 0 & 0 & 0 & 0 & (2) & (2) & 0 & $4(6)$ \\
\hline 3 & 1 & 0 & 3 & 0 & 1 & 0 & $1(1)$ & 0 & 0 & 0 & 0 & $6(1)$ \\
\hline 4 & 1 & 1 & (2) & 0 & 1 & (1) & 1 & (2) & 0 & 0 & (1) & $4(6)$ \\
\hline 5 & 1 & 0 & 0 & 0 & 0 & (2) & (1) & 1 & 0 & 0 & 0 & $2(3)$ \\
\hline 6 & 1 & 0 & (1) & 0 & 1 & 0 & 0 & 0 & 1 & 0 & (2) & $3(3)$ \\
\hline 7 & 0 & 0 & 0 & (1) & 0 & 0 & 0 & 0 & (1) & 0 & (5) & $0(7)$ \\
\hline 8 & 0 & 0 & 0 & 0 & (1) & (2) & 0 & (2) & (2) & 1 & (2) & $1(9)$ \\
\hline 9 & (1) & 0 & 0 & (1) & 0 & $2(1)$ & 2 & (1) & (1) & 0 & (9) & $4(14)$ \\
\hline 10 & (1) & 0 & 0 & 1 & 0 & 0 & 0 & 2 & 0 & 0 & (15) & $3(16)$ \\
\hline Total & $4(3)$ & $4(0)$ & $5(4)$ & $4(2)$ & $3(2)$ & $2(6)$ & $4(2)$ & $3(5)$ & $1(7)$ & $1(7)$ & $0(38)$ & $31(76)$ \\
\hline
\end{tabular}
spaced in between. ditch.

**Ditch refers to natural drainage ditch running from upland to river. Transects were at right angles to that $* * *$ Composite residue of all vegetative material from corresponding transect. 
published descriptions (Jones \& Anthony 1964, Pechuman 1972).

\section{RESULTS AND DISCUSSION}

In 1971 (TABLe 2) larval Tabanidae were recovered from $47 \%$ of the soil samples, an overall average of 1.05 larvae per sample. Only 2 species were recovered: Chrysops fuliginosus $(72 \%)$ and Tabanus nigrovittatus (28\%).

In 1972 (TABLE 3) $76 \%$ of the samples contained larval Tabanidae. An average of 2.75 larvae were recovered from each of the 71 samples. Although the majority of the tabanid larvae were small, $25 \%$ were reared to adults (21 C. fuliginosus and $3 T$. nigrovittatus) or identified in the larval stage by Dr J. Freeman (6 T. nigrovittatus sp. 3) or Dr H. Teskey (20 C. fuliginosus). As in 1971, only 2 species were recovered: C. fuliginosus $(82 \%)$ and T. nigrovittatus $(18 \%)$.

The data from the 2 successive years of larval sampling indicate that the larvae of both tabanid species were distributed throughout the Spartina alterniflora marsh with no apparent influence of the natural drainage ditch. This is contrary to some of the data and consistent with other data reported from the more northern New Jersey marshes (Rockel \& Hansens 1970a, b, Freeman \& Hansens 1972).
Different sampling methods (digging, washing, Berlese funnels and larviciding) as well as different locations are important factors contributing to these variable results. It should be noted, however, that our marsh was regularly inundated with tide water and therefore had no opportunity to dry. This is unlike many of the salt marshes further north along the Atlantic Coast of the United States. Those marshes are frequently dominated by Spartina patens with $S$. alterniflora found only near the margin of ditches. In this respect, the entire Spartina marsh on Newport River could be considered equivalent to the ditch margins of the more northern $S$. patens marshes. It is also possible that the variant " $T$. sp. 3" is more abundant in the more northern areas and is found more often in proximity to drainage ditches. In any event, it appears that it is not possible to generalize on the abundance of tabanid larvae in relation to drainage ditches in coastal salt marshes. The larval habitats should be characterized in other terms such as species of vegetation, soil type and the tidal regime over many months. Tide records for short periods (such as 6 weeks as used by Rockel \& Hansens 1970b) can be misleading due to seasonal and lunar variables and are not reliable for characterizing the larval sites for salt marsh tabanids, which are in the immature stages for about a year.

TABLE 3. Recovery of larval Tabanidae from soil up to $20 \mathrm{~m}$ from a natural drainage ditch marsh, Newport River, Morehead City, N.C., Mar.-Apr. 1972. Numbers indicate total numbers of tabanid larvae recovered from each sample. Numbers of specimens identified to species are in parentheses ( ) for Chrysops fuliginosus and in brackets [ ] for Tabanus nigrovittatus.*

\begin{tabular}{|c|c|c|c|c|c|}
\hline \multirow{2}{*}{$\begin{array}{l}\text { Transect } \\
\text { No.** }\end{array}$} & \multicolumn{5}{|c|}{ METERS FROM DRAINAGE DITCH*** } \\
\hline & 0 & 5 & 10 & 20 & Total \\
\hline$\overline{1}$ & $6(2)$ & 2 & 2 & 0 & $10(2)$ \\
\hline 2 & $5[2]$ & 1 & 0 & 0 & $6[2]$ \\
\hline 3 & 5 & $1(1)$ & $5(1)$ & $4(2)$ & $15(4)$ \\
\hline 4 & 2 & 0 & 2 & 0 & 4 \\
\hline 5 & 6 & $4[1]$ & 4 & 1 & $15[1]$ \\
\hline 6 & 0 & $3[1]$ & 0 & 3 & $6[1]$ \\
\hline 7 & 1 & $2[1]$ & 2 & $4(3)$ & $9(3)[1]$ \\
\hline 8 & $3[2]$ & 0 & $4(2)$ & 2 & $9(2)[2]$ \\
\hline 9 & $8(2)$ & 0 & $8(3)$ & $7(3)$ & $23(8)$ \\
\hline 10 & $1[1]$. & 6 & 0 & 1 & $8[1]$ \\
\hline 11 & 0 & 5 & 0 & 4 & 9 \\
\hline 12 & 1 & 0 & $2(2)$ & 3 & $6(2)$ \\
\hline 13 & 1 & $14(3)$ & $4(1)$ & 3 & $22(4)$ \\
\hline 14 & 0 & $15(4)[1]$ & 2 & 4 & $21(4)[1]$ \\
\hline 15 & $3(1)$ & $4(2)$ & $8(1)$ & $8(2)$ & $23(6)$ \\
\hline 16 & 1 & $2(1)$ & $1(1)$ & 1 & $5(2)$ \\
\hline 17 & 1 & $3(3)$ & 0 & $1(1)$ & $5(4)$ \\
\hline 18 & 0 & 0 & 0 & - & 0 \\
\hline Total & $44(5)[5]$ & $62(14)[4]$ & $44(11)$ & $46(11)$ & $196(41)[9]$ \\
\hline
\end{tabular}

*3 reared and identified as adults; 6 larvae identified as "T. sp. 3" by J. V. Freeman.

**Transect $\# 1$ was on the edge of the upland perimeter ditch, transect $\# 18$ near the edge of the river, and other transects were equally spaced $5 \mathrm{~m}$ apart in between.

***Ditch refers to natural drainage ditch running from upland to the river. Transects were at right angles to the ditch. 
The findings of these pest species of Tabanidae in their larval stages throughout the Spartina alterniflora salt marsh in the study area suggests that acceptable control measures directed against the larval stages are unlikely. The extensive marshes of this type presumably support a similar level of tabanid production. The prospects for implementing larval control measures (acceptable measures are not presently available) would be enhanced if the tabanid larvae were more localized in the marshes.

Acknowledgments: We are grateful to Drs H. J. Teskey, J. V. Freeman and M. A. Tidwell for identification of larvae and Dr L. L. Pechuman for identification of adults. The sampling and processing were greatly expedited by the help of W. Smith, J. Chang, D. Oglesby and R. Blankenship.

\section{LITERATURE CITED}

Adams, D. A. 1963. Factors influencing vascular plant zonation in North Carolina salt marshes. Ecology 44: 44556.

Bailey, N. S. 1948. A mass collection and population technique for larvae of Tabanidae (Diptera). Bull. Brooklyn Ent. Soc. 43: 22-29.

Cooper, A. W. 1969. Salt marshes, p. 567-611. In: Odum, H. T., B. J. Copeland, and E. A. McMahan (Eds.). Coastal ecological systems of the United States. A source book for estuarine planning, Vol. 1. Institute of Marine Sciences, University of North Carolina.

Edwards, T. D., J. C. Dukes \& R. C. Axtell. 1974. Soilwashing apparatus for recovery of tabanid larvae and other invertebrates. J. Georgia Ent. Soc. (In press).

Freeman, J. V. and E. J. Hansens. 1972. Collecting larvae of the saltmarsh greenhead Tabanus nigrovittatus and related species in New Jersey. Comparison of methods. J. Environ. Ent. 1: 653-58.

Jamnback, H. \& W. Wall. 1959. The common salt marsh Tabanidae of Long Island, New York. New York State Mus. Sci. Serv. Bull. 735.77 p.

Jones, C. M. \& D. W. Anthony. 1964. The Tabanidae (Diptera) of Florida. U.S. Dep. Agr. Tech Bull. 1295: 1-85.

Mooring, M. T., A. W. Cooper, and E. D. Seneca. 1971. Seed germination and evidence for height ectophenes in Spartina alterniflora from North Carolina. Amer. J. Bot. 58: 48-55.

Pechuman, L. L. 1972. The horse flies and deer flies of New York (Diptera, Tabanidae). Search (Cornell U. Agr. Exp. Sta.) 2: 72 p.

Roberts, R. H. 1966. A technique for rearing the immature stages of Tabanidae (Diptera). Ent. News 77: 79-82.

Rockel, E. G. 1969. Marsh physiography: influence on distribution of intertidal organisms. Proc. N. J. Mosq. Extermin. Assoc. 56: 102-15.

Rockel, E. G. \& E. J. Hansens. 1970a. Emergence and flight activity of salt-marsh horse flies and deer flies. Ann. Ent. Soc. Amer. 63: 27-31.

1970b. Distribution of larval horse flies and deer flies (Diptera: Tabanidae) of a New Jersey salt-marsh. Ann. Ent. Soc. Amer. 63: 681-84.

Teskey, H. J. 1962 . A method and apparatus for collecting larvae of Tabanidae (Diptera) and other invertebrate inhabitants of wet lands. Proc. Ent. Soc. Ont. 92: 204-06.

1969. Larvae and pupae of eastern North American Tabanidae (Diptera). Ent. Soc. Can. Mem. 63: 147 p.

Wall, W. \& H. Jamnback. 1957. Sampling methods used in estimating larval reproduction of salt-marsh tabanids. J. Econ. Ent. 50: 389-91.

Wall, w. J., Jr. \& O. W. Doane, Jr. 1960. A preliminary study of the bloodsucking Diptera on Cape Cod, Massachusetts. Mosquito Neres 20: 39-44. 